\title{
Risk Assessment
}

Humanitarian organizations work to address the needs of those affected by natural disaster, famine, internal conflict, or international war; thus their activities are necessary in high-risk contexts. In these cases, humanitarian action is prompted by the risk to civilians. However, these situations also generate risks for both individual humanitarian actors and humanitarian organizations. Humanitarian organizations often define risk as a consideration of the possibility of a detrimental event, and the potential impact generated if the event occurs. It can also be expressed as Risk $=$ Likelihood $\times$ Impact (Stoddard et al. 2016). Here, likelihood refers to the potential of a harmful event, while impact refers to the potential severity of an event.

In a global context, where the rules of war and human rights are often perverted and humanitarian need is high, organizations must allocate more time, consideration, and resources to assessing the risks of their work. Risk management in the humanitarian industry means "a formalized system for forecasting, weighing and preparing for possible risks in order to minimize their impact" (Czwarno, Haver, and Stoddard 2016: 8). There are countless risks for organizations offering humanitarian aid to populations affected by war, conflict, displacement, natural disaster, and so on. Potential fiduciary risk, reputational risk, operational risk, residual risk, and risks to staff are ever looming on the horizon of humanitarian activities in increasingly insecure contexts. Some define fiduciary risk as "the possibility that resources will not be used as intended" which includes, but is not limited to, "corruption, fraud, embezzlement, theft and diversion of assets" (Czwarno, Haver, and Stoddard 2016: 3). Reputational risk is the potential for an occurrence that will ultimately damage the public image of an organization. For example, irreparable reputational risk could ensue if an organization makes a move that will damage their credibility, such as misrepresentation of need or impact, misallocation of funds, or intentional diversion of earmarked funds to a project for which the financial assistance was not originally allocated (Sarazen 2018). High profile duty of care incidents could also damage the public perception of a humanitarian organization. Risks to staff can present as emotional, physical or financial, and can range from street harassment to death (Czwarno, Haver, and Stoddard 2016).

Some organizations conduct risk assessments through rigorous frameworks, while others consider risk on an ad hoc basis or via non-standard methodology. Each system, either formal or informal, assists organizations in determining if and how their humanitarian operations may be exposed to danger. Risk 
assessment processes are not currently standardized across the humanitarian industry. Formal risk assessments are often conducted by program and security teams tasked with decision-making processes that could either prompt or curb humanitarian activities. Further, risk assessments form part of the security management systems of humanitarian organizations, meaning that they are often focused on potential risks to staff or the risks of implementing programs in certain areas, rather than the risk of non-delivery of aid.

Contrary to popular belief, aid workers who operate in high risk contexts are not primarily expatriate staff representing organizations headquartered far away. Traditional risk assessments, if implemented at all, have been critiqued for weighing the risks posed to international staff more heavily than the risks posed to national staff. In fact, incident and demographic numbers suggest that, in some cases, national aid staff are more likely to be targeted by violence (Aid Worker Security Database 2017; Bickley 2017; Sarazen 2018).

In contexts where there is a high need for the intervention of international organizations and non-governmental organizations because of violence and human rights violations, the perpetrators of the violence make the risk assessment matrices even more complex. In short, higher risks provoke higher stakes for all involved (Sarazen 2018).

Ultimately, "risk management, no matter how well-conceived and implemented, cannot eliminate risk; it only reduces the likelihood of its occurrence and mitigates against the potential consequences" of threats (Stoddard 2016). Improved risk management strategies can and should be designed for and adapted to the new frontier of humanitarianism in years to come, especially to counteract the relative scarcity of humanitarian aid in increasingly high-risk contexts (Stoddard et al. 2016).

\section{Alexandra Sarazen}

\section{References}

Aid Worker Security Database (2017) https://aidworkersecurity.org/.

Bickley, S. (2017) Security Risk Management: A Basic Guide for Smaller NGos. European Interagency Security Forum.

Czwarno, M., Haver, K., Stoddard, A. (2016) NGos and Risk: How International Humanitarian Actors Manage Uncertainty. Humanitarian Outcomes.

Sarazen, A. (2018) Accountability in the Balance: Exploring the Paradox of Program Criticality on the High Risk Frontier of Humanitarian Assistance. NTNU. 
Stoddard, A. (2016) Residual Risk Acceptance: An Advocacy Guidance Note. Humanitarian Outcomes.

Stoddard, A. et al. (2016) The Effects of Insecurity on Humanitarian Coverage. SAVE.

\section{Rule of Law}

Political leaders and legal thinkers across the globe have unanimously defended the rule of law as an essential, universal good. In fact, it has become "the preeminent legitimating political ideal in the world today" (Tamanaha 2004:4), as compelling as it is seemingly self-evident: a "ubiquitous and 'natural' formulation" (Rajkovic 2010: 35).

Yet the rule of law eludes any clear definition. Whether the rule of law includes the protection of individual rights or ideals of democracy, whether it is to be understood in strictly formalistic terms (i.e. abiding by written legal rules and limiting law-making power), or whether it refers to the conditions for the fulfillment of humanity's "legitimate aspirations and dignity" (International Commission of Jurists 1959: VII, in Tamanaha 2004: 2) remains open to question. What is clear, however, is that the more the rule of law is invoked (and the more money is spent on its realization worldwide), the more concerns emerge regarding its forms of implementation, especially in contexts of post-conflict and massive humanitarian responses.

Since the early 1990s, humanitarian and "transitional" settings have been underpinned by a lingua franca of combined economic and legal development in the name of the rule of law. International donors started seeing the rule of law (in terms of government accountability and transparency, and the independence of the judiciary) as indispensable for, and inseparable from, economic development and the creation of a "level playing field' for economic actors" (Channell 2005: 3). The World Bank and the International Monetary Fund imposed the implementation of the rule of law as a condition of financial assistance on recipient countries, and millions have been spent on legal reforms, largely via humanitarian channels, in places such as Kosovo, Rwanda, and Afghanistan. Moreover, a renewed United Nations focus on civilian protection has led humanitarian actors to postulate a strong link between protection and the rule of law, and thus to include access to justice programs geared at displaced and war-affected populations in their postwar reconstruction efforts. 